\title{
Mudanças no mundo do trabal ho: Acertos e desacertos na proposta curricular para o Ensino Médio (Resolução CNE 03/98). Diferenças entre formação técnica e formação tecnológica*
}

\author{
Maria Rita Neto Sales Oliveira**
}

RESUMO - O texto analisa a nova proposta curricular para o Ensino Médio, particularmente no que se refere a educação profissional, focalizando a diferença entre formação técnica e tecnológica, nos âmbitos do discurso oficial e da implantação da proposta. Aborda-se a questão de contradições no estudo da relação entre a proposta e as mudanças no setor produtivo, ligadas às novas exigências de formação e qualificação profissional. Com base em dados de pesquisa empírica, a partir da implantação da reforma em escolas técnicas, o texto discute propriedades da pratica escolar no ensino tecnológico, sinalizando a perda de identidade dessas escolas, no contexto da reforma, no sentido de viabilizar um processo formativo de educação tecnológica comprometido com a democratização educacional.

Palavras-chave: Ensino Médio, educação tecnológica, reforma do Ensino Técnico.

Este texto toma como objeto de análise crítica a proposta curricular para o Ensino Médio em seus aspectos legais, historicizando-a e refletindo sobre seus acertos e desacertos, aqui entendidos como implicações, nos

\footnotetext{
* Texto que serviu de base para o trabalho apresentado pela autora, em sessão especial, na $22^{a}$ Reunião Anual da Anped, realizada em Caxambu, de 26 a 30/9/99.

${ }^{\star *}$ Professora titular da FaE-UFMG e Adjunta doutora do Cefet/MG. Email: mariarita@ dppg.cefetmg.br
} 
processos formativos escolares, dos fundamentos e procedimentos defendidos pela proposta, com os quais se pode ou não concordar segundo diferentes posições e interesses em jogo.

Além disso, o subtítulo apresentado - Diferenças entre formação técnica e formação tecnológica - e a atividade profissional da autora, exercida nos últimos anos, exatamente, em uma Instituição de Educação Tecnológica - o Centro Federal de Educação Tecnológica de Minas Gerais (CEFET$M G$ ) - definem que se aborde o tema a partir dessas diferenças, em suas relações com a denominada educação tecnológica.

A propósito, a educação tecnológica e o Ensino Técnico têm sido objeto de estudo em vários fóruns de debate e objeto de novas regulamentações no interior das políticas públicas atuais sobre educação tecnológica no País. Nesse contexto, situa-se o Decreto n. 2208 de 17 de abril de 97 referente à Reforma do Ensino Técnico (BRASIL, 1997). Esse Decreto é retomado pelo Parecer 15/98 (CNE-CEB, 1998) que integra a Resolução 3/98 (CNE - CEB, 1998b), no que se refere à articulação entre o ensino regular e a educação profissional, e, conjuntamente, às relações entre a formação geral e a preparação para o trabalho no nível médio.

A partir dessas considerações, o texto aborda o tema em dois âmbitos: o âmbito das diretrizes, tal como presentes nos documentos legais em pauta; e o âmbito da implantação da proposta curricular para o Ensino Médio em escolas técnicas, privilegiando o último, trazendo como contribuição o discurso da escola sobre a reforma. Entretanto, nos dois âmbitos, as considerações feitas têm base no trabalho teórico-prático da autora no cotidiano de instituições escolares e possuem o caráter de questões mais do que de afirmações ou conclusões; elas são fruto de uma aproximação possível e inicial do entendimento do tema em pauta, a partir da posição de defesa de uma educação escolar que se materialize como fator ligado ao fortalecimento do pluralismo político e cultural, e fator de superação das relações de exclusão societárias.

\section{Formação técnica e formação tecnológica}

Nesta década, o tema das diferenças entre formação técnica e formação tecnológica tem sido objeto de intenso e extenso debate nas Instituições de Educação Tecnológica no País.

Essas diferenças têm sido apresentadas como argumento para a resistência das instituições à implantação da Reforma do Ensino Técnico, tal 
como definida pelo Decreto 2208/97. Esta estaria determinando a aproximação dos processos formativos escolares de educação profissional, vigentes nessas instituições, aos processos de treinamento do trabalhador no mero domínio das técnicas de execução de atividades e tarefas, no setor produtivo e de serviços, e, portanto, à uma formação meramente técnica. E, consequentemente, estaria afastando a escola do objetivo de uma formação tecnológica. Esta envolveria, entre outros, o compromisso com o domínio, por parte do trabalhador, dos processos físicos e organizacionais ligados aos arranjos materiais e sociais, e do conhecimento aplicado e aplicável, pelo domínio dos princípios científicos e tecnológicos próprios a um determinado ramo de atividade humana.

Além disso, essas diferenças têm sido apontadas na definição de novas propostas pedagógicas para as escolas que, de um lado, ultrapassem as suas práticas, ainda presas ao senso comum e à racionalidade técnica, e, de outro, se construam como alternativas às propostas oficiais que vêm sendo definidas para o Sistema de Educação Tecnológica do País.

Mas que outras características definem uma proposta de educação tecnológica, relacionada à formação tecnológica e não limitada àquela formação técnica vinculada a treinamento?

De forma sintética, elas se referem a uma dada concepção de tecnologias e uma dada concepção de educação.

Em relação às tecnologias, envolve o seu entendimento como:

- produtos da ação humana, historicamente construídos, expressando relações sociais das quais dependem, mas que também são influenciadas por eles. Assim, os produtos e processos tecnológicos são considerados artefatos sociais e culturais, que carregam consigo relações de poder, intenções e interesses diversos;

- artefatos mediadores da interação social e cognitiva do ser humano com as bases materiais da sociedade;

- recursos que, se de um lado não possuem características do sagrado - de poder infinito e perene -, que demandaria celebração, de outro, também não são artefatos destituídos de cultura e criados apenas para serem consumidos e trocados como mercadoria.

Em relação à educação, defende-se que:

- a educação escolar não seja equacionada nos limites da modernização econômica do país e dos interesses empresariais, reduzindo direitos à educação aos imperativos do mercado de trabalho; 
- sejam valorizadas a importância e a possibilidade da exploração das capacidades, dos produtos e processos tecnológicos para a ruptura das relações de exclusão societárias, posto que são constituídos no jogo de forças e interesses contraditórios dos diferentes sujeitos sociais;

- diminua-se a ênfase, muitas vezes comum nas instituições de educação tecnológica, à importância do ensino para, com, e da tecnologia, em benefício de um processo que lida com a tecnologia a serviço do ensino e o ensino sobre a tecnologia;

- e, finalmente, implique uma formação que alie cultura e produção, ciência e técnica, atividade intelectual e atividade manual; que seja fundada nos processos educativos da prática social em que o trabalho concreto produtivo e reprodutivo da existência humana material e sociocultural aparece como propriedade fundamental. Dentro disso, trabalho e escola não são entendidos apenas como espaços em que se realizam, respectivamente, a produção ou o preparo para o exercício de atividades produtivas.

Essa concepção de formação, de educação tecnológica, integraria, de forma democrática, a educação geral e a formação profissional, enquanto direito do cidadão, em um projeto construído coletivamente pela escola, envolvendo flexibilização na oferta de programas, que habilitassem o exercício profissional vocacionado dos alunos, a partir de demandas sociais devidamente identificadas. Esses projetos seriam elaborados no contexto de uma gestão democrática que ultrapassa a estrutura, não raro, autoritária em instituições de educação tecnológica, e luta pela preservação da autonomia escolar em suas relações com a indústria e o setor produtivo em geral.

Importa lembrar que essa concepção está fortemente ligada à prática de escolas, historicamente comprometidas com a educação dos trabalhadores - as escolas técnicas -, e que vieram construindo uma oferta competente de formação geral e de preparação para o trabalho integrada, no nível médio. No entanto, ela não é consensual no interior dessas instituições.

À luz dessas considerações, levantam-se, entre outras, algumas questões:

- Em que medida os fundamentos e procedimentos relativos às diretrizes curriculares para o Ensino Médio, presentes na Resolução 03/98 e articulados com o que propõe o Decreto 2208/97 aproximam-se ou distanciam-se da concepção de formação, de educação tecnológica aqui caracterizada?

- Em que medida as diretrizes são ou não orgânicas ao processo de globalização da economia de mercado, às mudanças operadas no se- 
tor produtivo e de serviços ligadas ao paradigma da flexibilidade e integração, e ao papel central atribuído aos recursos humanos na adoção e implantação desse paradigma? Enfim, em que medida as diretrizes são orgânicas ao estágio atual de acumulação capitalista e, conjuntamente, às novas exigências de formação e qualificação do trabalhador? E aqui importa lembrar a multiplicidade e, juntamente, a ambigüidade, de funções do Ensino Médio, construídas historicamente: formativa e propedêutica (educação geral) $X$ profissionalizante (educação especial e de preparação para o trabalho); e, no caso do Ensino Técnico, a função ora moralizante, compensatória, contenedora das pressões por níveis mais elevados de escolarização, ora de iniciação, preparação, qualificação para o trabalho, esta última acompanhada mais recentemente pela ênfase nas funções de requalificação, reprofissionalização e atualização para o trabalho, à luz do conceito de empregabilidade.

\section{No âmbito das diretrizes - o discurso oficial}

Consideração preliminar

Em primeiro lugar, à luz das considerações já feitas, encontra-se uma primeira preocupação com as diretrizes expressas nos documentos mencionados. Essa preocupação refere-se à elaboração teórica dos documentos, que é de tal ordem sofisticada, que se pode hipotetizar, com um certo grau de certeza, dificuldades na sua decodificação por parte da escola. Esta, no entanto, deve, segundo os mesmos documentos, elaborar a sua proposta pedagógica, a partir das Diretrizes Curriculares Nacionais neles presentes. A situação se agrava na condição dos docentes das disciplinas do currículo do Ensino Técnico que podem ser professores, instrutores ou monitores, segundo o Decreto 2208/97. Embora possa parecer pouco importante à primeira vista, esse aspecto pode ter implicações profundas acerca das relações entre o que se propõe no âmbito das políticas educacionais e o que se implanta, de fato, no âmbito da educação escolar.

Diretrizes e mudanças no setor produtivo: Uma expressão de contradições?

Levantar as questões aqui postas implica rever análises ${ }^{1}$ feitas sobre a estrutura e a organização curricular proposta para a educação 
profissional de nível médio, e pelas quais se coloca em cheque a funcionalidade da proposta, até mesmo para as novas exigências de qualificação do trabalhador, à luz do paradigma da empresa integrada e flexível.

Relembrando: a nova legislação propõe tipos e, sobretudo, níveis diferenciados de educação profissional, nitidamente dirigidos a diferentes alunos, segundo, obviamente, sua condição de classe.

Assim, a educação profissional, destinada a capacitar jovens e adultos para o exercício de atividades produtivas, compreende três níveis (básico, técnico e tecnológico); o tecnológico, estruturado segundo os diferentes setores da economia, é destinado a egressos do Ensino Médio e técnico; o básico é uma modalidade de educação não formal, ligada às demandas do mundo do trabalho, oferecida para trabalhadores, independente da escolaridade prévia e conferindo certificado de qualificação profissional; e o técnico (nível médio) destina-se à habilitação profissional para alunos egressos do Ensino Médio ou matriculados neste. Esse nível médio tem organização curricular própria e independente do Ensino Médio regular, podendo ser oferecido sob a forma de módulos, que podem ser cursados em diferentes instituições, conferindo certificados específicos de qualificação. Os conjuntos de certificados, ligados a uma dada habilitação correspondem a diploma de técnico de nível médio. O diploma é expedido pelo estabelecimento de ensino que confere o último certificado de qualificação, desde que o interessado apresente o certificado de conclusão do Ensino Médio regular.

Em relação ao tema aqui tratado, segundo os documentos oficiais/ legais - o Decreto, a Resolução e o Parecer em pauta -, a organização e a estrutura definidas para a educação profissional encontrariam fundamento em alguns pontos básicos:

- busca da ampliação e da melhoria de qualidade da educação básica, destacando-se a educação tecnológica básica, para o exercício da cidadania e acesso às atividades produtivas;

- proposta de educação, vinculada à flexibilidade e à complexidade tecnológica do trabalho, mas devendo ser básica para a "formação de todos e para todos os tipos de trabalho", segundo o Parecer em pauta. Os diferentes percursos previstos não excluiriam a continuidade dos estudos, mas podem, também nos termos do Parecer, "incluir períodos de aprendizagem de nível superior ou não - intercalados com experiência de trabalho produtivo";

- proposta de construção de um "novo humanismo", que, ainda segundo o Parecer, possibilita "integrar a formação para o trabalho num projeto mais ambicioso de desenvolvimento da pessoa humana", relacionado 
com competências "valorizadas pelas novas formas de produção pós-industrial que se instalam nas economias contemporâneas";

- e, finalmente, o fortalecimento das relações entre cultura e trabalho, ciência, técnica e tecnologia, e a superação da dicotomia entre trabalho intelectual e trabalho manual, valorizando-se a educação profissional propriamente dita.

Assim, no âmbito desses fundamentos, poder-se-ia advogar que as diretrizes propostas se distanciam de uma educação estritamente vinculada à formação técnica e se aproximam de um processo de formação tecnológica, tal como aqui definida.

A rigor, embora no Parecer em pauta acabe-se definindo, por exemplo, trabalho como um espaço - o do mercado de trabalho -, e tecnologia nos limites de um conteúdo didático-pedagógico das habilidades e competências a serem adquiridas pelo educando, nas diferentes áreas curriculares, não se pode negar que as diretrizes propostas buscam equilibrar-se sobre a polarização: um projeto democrático de formação de cidadania calcado na igualdade e liberdade, aproximando-se de uma proposta de educação tecnológica para todos, e um projeto de modernização calcado na equidade e voltado para o mercado, e que se distanciaria dessa proposta.

Nessa condição, a despeito de todo o visível esforço de argumentação no sentido de que se estaria propondo uma escola unitária e tecnológica para todos, no contexto das novas características dos setores produtivo e de serviços, sobretudo pelas definições e procedimentos de organização e estruturação curricular propostos, não há como negar, um ponto nevrálgico: o reforço à denominada dualidade estrutural, historicamente presente no Ensino Médio e que implica trajetórias escolares diferentes, hierarquizadas, de qualidade diferente, para clientelas diversificadas, cujas diferenças não são, por certo, explicadas por competências que elas trazem, com base em critérios naturais e/ou de esforço e mérito individuais.

Ligado ao exposto, tal como definida pelos mecanismos previstos, a flexibilidade de oferta, de acesso e de terminalidade referentes a diferentes cursos e níveis de ensino, particularmente no que se refere à articulação entre a educação básica e a educação profissional, se, de um lado, implica diversidade de oferta educacional em uma formação social marcada pelo pluralismo sócio-cultural, de outro, implica, sim, dificuldades à continuidade de estudos por parte das camadas menos favorecidas, para quem a não integração na escola entre os tempos e espaços de aprendi- 
zagem geral e os tempos e espaços de formação profissional não favorece essa continuidade, e sequer a sua sólida formação profissional para o exercício necessário de atividades produtivas ${ }^{2}$.

Dentro disso, tal como previsto, como viabilizar o que a própria legislação em pauta busca defender em termos de preservação de tempos e espaços de formação geral para todos e de educação profissional vinculada às necessidades diferenciadas dos jovens brasileiros?

As considerações anteriores reafirmam a posição de que as diretrizes, em sua organicidade com o estágio atual de acumulação capitalista $e$ com as novas exigências de formação e qualificação do trabalhador, expressariam a contradição da importância atribuída à disseminação da educação escolar, a partir da incorporação da ciência à produção, pela qual, apesar de o saber ser propriedade da classe detentora dos meios de produção, não se pode excluir os trabalhadores da posse desse saber, posto que eles necessitam dele para produzir. Mas, importa registrar, conforme Enguita (1993, p.202),

O que o mundo da produção demanda da escola não é a formação de uma força de trabalho indiferenciada. O que demanda é uma massa de força de trabalho social, estruturada vertical e horizontalmente, quer dizer, atendendo, por um lado, a divisão entre funções de direção e de execução, com toda a gama intermediária, e, por outro, à divisão em especialidades dentro de um mesmo nível.

Tudo isso permitiria perguntar: em que medida, pela nova proposta, a velha dualidade estrutural, agora com roupagem nova, estaria invertendo o pouco prestígio da educação profissional, historicamente reservada aos desvalidos da sorte, para o seu maior prestígio, sim, mas apenas para os níveis (técnico e tecnológico) cujas exigências de entrada, permanência e saída não favorecem a continuidade dos estudos por parte de quem precisa alternar tempos de escola com tempos de trabalho? E, com isso, pergunta-se, novamente se, e, em que medida, a proposta expressa ou não aquela concepção de formação, de educação tecnológica aqui defendida, porquanto a estrutura dual e a fragmentação inerente à proposta não favorece, por certo, a integração entre cultura e produção, ciência e técnica, atividade intelectual e atividade manual própria da educação tecnológica...

Uma nova aproximação no tratamento desta questão poderia ser buscada no trabalho que os sujeitos escolares constróem e/ou podem construir. Assim, quais têm sido as implicações da Reforma no chão de 
escola, onde ela se realiza, no sentido de aproximá-la ou distanciá-la da concepção de formação tecnológica apresentada?

\section{No âmbito da implantação - o discurso da escola}

Os dados aqui apresentados fazem parte de um projeto de investigação em que se realizou uma pesquisa empírica em/com três escolas de um Centro de Educação Tecnológica do País, no $1^{\circ}$ semestre de 1998, que já haviam implantado a Reforma do Ensino Técnico, tal como definida pelo Decreto 2208/97.

A questão central referia-se ao relacionamento entre a organização do saber escolar e as modificações no setor produtivo. Do ponto de vista metodológico, entre outras atividades, foram realizadas 38 entrevistas semi-estruturadas, envolvendo os diferentes segmentos da instituição: corpos discente e docente, técnico-administrativo e representantes da Associação de Pais e Mestres.

A maioria das entrevistas foi gravada e, a partir de leitura e várias releituras dos textos, foram sendo identificadas as propriedades da prática pedagógica do ensino tecnológico nessas escolas. Os textos integrais das entrevistas gravadas de 24 sujeitos, aleatoriamente definidos, foram sendo, então, divididos, e suas partes agrupadas, reagrupadas em torno dessas categorias, gerando dois conjuntos de informações: um sobre a prática no ensino tecnológico, em geral, com 1351 manifestações distribuídas por 14 categorias, e outro sobre essa prática na condição da reforma, envolvendo 913 manifestações, também distribuídas pelas mesmas categorias.

\section{A Reforma do Ensino Técnico}

$\mathrm{Na}$ análise dos dados, uma constatação inicial foi a de que a Reforma do Ensino Técnico assume o papel de personagem central no momento então vivido pelas escolas. Fica evidente a ampla extensão das mudanças que as escolas estariam experimentando, a partir dessa reforma, mas também a intensa resistência a ela. E com isso, a característica desse momento parece ter propiciado condições favoráveis para um entendimento mais rico não apenas sobre a implantação da Reforma, o que aliás não era o objetivo da pesquisa, mas, também, sobre a natureza da prática pedagógica escolar. Em outras palavras, num contexto de uma reforma, que estaria ameaçando a perda da identidade das escolas técnicas, tal como percebida e assumida 
pelos sujeitos em seu interior, estes expressariam aquilo que, de fato, Ihes importa ou não lhes importa, o que é secundário e acidental versus o que é essencial na definição do trabalho escolar, e aquilo que é mais ou menos determinado por intervenções não nascidas deste/neste trabalho.

Dessa forma, se de um lado a condição da Reforma desviou a pesquisa daquilo a que ela se propunha, de outro, possibilitou o enriquecimento da compreensão da prática escolar em instituições de educação tecnológica, e, ao mesmo tempo, viabilizou um entendimento do processo, ainda que inicial, de implantação da Reforma nas escolas.

Importa registrar que, segundo os entrevistados, as mudanças nas escolas, em função da Reforma, envolveram, entre outros aspectos: a suspensão da oferta do Ensino Médio integrado para novos alunos, a oferta de um novo Ensino Médio regular com uma porcentagem da carga horária total reservada para disciplinas de caráter profissionalizante e a oferta de cursos técnicos sob a forma de módulos. As novas grades curriculares e os novos conteúdos de ensino foram reformulados no espaço da Coordenação Central e enviados para as escolas. Quanto à avaliação discente, houve a substituição do sistema numérico (pontos de 0 a 10) em que se avaliava basicamente conhecimento, por um sistema de conceitos (MB, B, I), reforçando-se a idéia de se avaliar o que é denominado de conhecimentos, atitudes e comportamento ou habilidades. Além disso, foi cancelada a exigência de o aluno cumprir pelo menos $75 \%$ da carga horária total de cada disciplina para efeito de aprovação, pois, pelo novo sistema, o aluno deverá cumprir esta porcentagem em relação à carga horária total do curso, com base na defesa de sua formação global. Quanto à avaliação docente, um sistema de pontuação/classificação elaborado anteriormente, envolvendo análise de curriculum vitae, e que não fora implantado, passou a vigorar em 1998, para atribuição de aulas e dispensa de professores.

Mas o que os sujeitos da escola falam sobre a Reforma? E como eles se referem à ela? A seguinte afirmação é expressiva:

A mudança mais significativa que a gente teve foi esta que a gente está passando agora: a Reforma do Ensino Técnico. Porque, até então, as mudanças eram fatos corriqueiros que vinham e tínhamos que acompanhar. Mas a Reforma do Ensino Técnico trouxe uma mudança grande para as escolas. (Sujeito 22)

Dentro disso, os entrevistados se referem à Reforma por meio de expressões que caracterizam destruição, corte: 
Nós saímos de férias e chegamos aqui com a bomba na nossa cabeça... (...)Há é a falência desses cursos técnicos... (Sujeito 01)

Foi uma mudança brusca mesmo. (Sujeito o2)

As coisas corriam muito bem, até que veio esta reformulação que foi paulatina. Não foi de uma hora para outra. Mas as pessoas não acreditavam que isso era possível... E o que acontece, apesar de tudo isso, veio devagarinho, paulatinamente, mas foi destruindo... (Sujeito 07)

... estamos pisando em ovos, tentando contemporizar todos os problemas ... (Sujeito 12).

Eu, particularmente, considero como o início de um caos no Ensino Técnico. Na destruição mesmo! (...) Que mudança é esta que corta pela metade?(Sujeito 15)

... se não tivesse cortado o outro sistema... (Sujeito 19)

Ao ser inquirido, aqui, o Secretário de Estado da Educação não soube explicar a que vinha esta proposta. Ou seja, tem deixado a desejar. O que a gente sabe é que teve um desmonte... (Sujeito 17)

Tudo aquilo que você dava no período integral, em que você fazia aquela intercomunicação entre as disciplinas, isso tudo se perdeu (Sujeito 20)

Só que em 97 nós recebemos este balde de gelo na cabeça que foi a nova LDB e o decreto 2.208 que acabou com o Ensino Técnico... o desastre está aí, está fixado. Agora nós temos que minimizar esse desastre, temos que correr atrás do prejuízo... Satisfaz alguns, não sei quem, mas satisfaz. E te garanto que não é à escola. É uma opinião particular. (Sujeito 21)

Dentre as manifestações emitidas, encontram-se 412 manifestações diferentes sobre a Reforma, em que mais de $80 \%$ implicam apreciações desfavoráveis, cujo conteúdo é esclarecedor sobre os limites concretos da Reforma na escola, na direção de se construir uma formação tecnológica, tal como a definida.

\section{As categorias da prática}

A partir dessas manifestações a preocupação que se teve foi, exatamente, a de tentar conteudizar de forma mais objetiva a quê, de fato, os sujeitos estavam se referindo. Em outras palavras, por que, para as escolas em pauta, a Reforma atual não é um fato corriqueiro como outras 
teriam sido? O que a Reforma muda e o que não muda nas escolas? $\mathrm{E}$ obviamente, o que definiria o trabalho pedagógico nas escolas, cujas mudanças estariam afetando tanto a vida escolar?

Com base na análise dos depoimentos dos entrevistados, a busca de respostas a essas questões levou inicialmente à identificação de três aspectos que apareceram como fundamentais na caracterização dessa prática: as regras e práticas de avaliação, a clientela e o currículo.

Em primeiro lugar, há evidências no sentido de que a identidade do trabalho escolar, baseado em um regime de regras e verdades definidas e bem conhecidas, em relação às quais os sujeitos se sentiam confortáveis, envolvia um dado sistema de avaliação de alunos e professores, cuja alteração, a partir da implantação da Reforma, representou mudança significativa e desconforto para eles. Aqui, não apenas a questão de quem define o sistema de avaliação e de como ele é definido parece importar, mas, também, o conteúdo em si de um novo sistema, que modificou as relações entre os sujeitos na escola, instalando, por exemplo, no caso da avaliação docente, uma lógica do correr atrás de pontos entre os professores.

$\mathrm{Na}$ fala de um entrevistado:

Não, simplesmente, com os cursos que estão em andamento, já fazer até mudanças, em termos de avaliações... Quer dizer, é mudar as regras do jogo, durante o jogo. (Sujeito 10)

E sobre cursos de capacitação docente:

Todo curso conta, mesmo que não seja promovido pelo Centro, desde que tenha afinidade com a área em que você está trabalhando. Mas os professores não solicitam muito. De certa forma porque a maioria dos professores, hoje, com este arrocho salarial que a gente está tendo, precisa dar 70 aulas por semana. Então, você não tem tempo, não está preocupado com isso, pelo menos em determinadas épocas do ano. Mas quando vai chegando a época de contar ponto para classificação, o pessoal começa a apavorar, a pedir, mas já não dá mais tempo. Então fica complicado. (Sujeito 21)

Ao lado disso, a nova grade curricular e a nova clientela da escola, em função da nova estrutura de oferta de cursos, apareceram como fatores muito importantes nas mudanças em curso. Assim, encontra-se: 
Basicamente, não vejo mudanças em outro aspecto que não a clientela e a grade curricular, que foram importantes. Isso é tão importante para definir o curso, que pode ser que, no meio do caminho, a gente chegue a esbarrar em alguma coisa. Mas se a gente conseguir adequar essa grade a um novo curso para trabalhar com essa nova clientela $(. . .)^{3}$ nós vamos ter que trabalhar mesmo. (Sujeito 22)

Em estreita relação com as questões de avaliação e clientela, os sujeitos manifestam preocupação sobre a permanência dos alunos nas escolas, enfatizando dúvidas acerca das novas condições destas, sob a reforma, que potencializariam a evasão escolar. Ilustram essa preocupação alguns depoimentos a seguir:

O que se pede é que não haja evasão. Não é o nosso caso, ainda, mas o que eu digo é que daqui a pouco vai ser assim... Não é pessimismo, é realidade, se não se transformar essa mesma realidade... (Sujeito 07)

O meu receio é com a desistência, com o não compromisso com o $2^{\circ} \mathrm{grau}$. A pessoa está estudando, mas qualquer coisa que aparecer que atrapalhe um pouquinho, ela vai acabar desistindo... Se você está vinculando o Ensino Técnico ao colegial, mesmo que ele (trata-se do aluno) não esteja gostando, ah não era isto que eu queria, ele vai até o fim porque vai terminar o $2^{\circ}$ grau. (Sujeito 19 )

Em segundo lugar, vários entrevistados, ao se referirem à clientela das escolas, posicionaram-se contra as mudanças, denunciando seu caráter elitizante, defendendo o acesso à educação pública gratuita e de qualidade, como direito do cidadão. Ao lado disso, os sujeitos expressaram suas representações sobre relações entre as escolas e a comunidade, salientando expectativas desta que estariam sendo frustradas pela Reforma atual. Fica evidente que as representações nas escolas sobre acesso à escolarização e relação escola e comunidade, ao lado da avaliação, clientela, currículo e evasão, constituem outras propriedades importantes na definição da prática nessas escolas, e estariam sendo afetadas pela Reforma. E, neste caso, não porque esta amplia as possibilidades de acesso e de atendimento a expectativas da população, mas, exatamente, porque as restringe.

Reforçando a importância das questões das condições de acesso escolar e do currículo na caracterização da prática, um dos entrevistados assim se expressa: 
Então tem pontos (referindo-se ao currículo) que a gente acha que poderiam ser alterados, para o bem do aluno, sempre pensando que a gente tem é que melhorar tudo. Então, esses seriam pontos que já dão uma idéia (referindo-se aos problemas com a reforma) além da questão do deslocamento. (Trata-se do deslocamento do aluno de uma escola para outra). (Sujeito 05)

Quanto às menções feitas a questões sobre currículo, em particular, a identidade das escolas não parece se abalar por mudanças nos conteúdos das disciplinas que ensinam, nos planos, métodos e recursos didáticos utilizados. Assim as mudanças nesses aspectos, no contexto da Reforma, não estariam incomodando os sujeitos entrevistados, ou, se estão incomodando, não são suficientemente fortes para abalarem os processos formativos escolares.

Isto se explicaria, no âmbito dos conteúdos, ou porque a voz do professor ou especialista acaba sendo ouvida, ou porque, nesse âmbito, não se consegue controlar a prática pedagógica, porquanto no espaço da sala de aula ainda há a prerrogativa da autonomia docente, ou, ainda, porque os conteúdos das disciplinas escolares não mudam mesmo... Dentro disso, a estrutura lógica da matéria e a lógica do estágio de desenvolvimento do aluno legitimam as não mudanças, em qualquer contexto de mudanças.

Da mesma forma que em relação aos conteúdos de ensino, em última instância, independente de reforma, a autonomia do professor sobre como ensinar parece ser preservada, mesmo quando se mudam os planos didáticos a revelia da sua posição. Os métodos e recursos didáticos e, até mesmo, as propostas didático-pedagógicas para a condução do processo de ensino e aprendizagem, não seriam afetados por reformas. No caso em pauta, as mudanças nesses aspectos, na condição da Reforma, não parecem, de um lado, terem sido implantadas de fato e, de outro, serem instrumento essencial de implantação dessa mesma Reforma. As falas seguintes são bem expressivas:

Então isto é o que foi colocado para nós. Tem que ensinar isto. Então, nós mudamos à nossa vontade. Não para piorar, para ser contra, mas para ter coerência naquilo que vamos dar para os alunos. (Sujeito 21)

Não sei se você percebeu, na conversa com os professores, que mudou muita coisa. Mas será que eles mudaram em relação às aulas, ou as aulas continuam sendo a mesma coisa? É, mudou 
muita coisa. Mudou a forma, um pouco o objetivo da aula, mas a aula em si não mudou. É gozado, não é? Onde deveria mudar, não mudou. (Sujeito 24)

A disciplina está lá, nós vamos dar aquilo que eles querem, só que vai ser no final do semestre, não na hora que eles querem. (Sujeito 21)

A gente usa a lousa, o apagador, o giz. Eu trabalho muito com textos com os alunos. Principalmente os temas mais atuais, a gente procura, eu xeroco e trago para eles. Levo os alunos para o laboratório. (Sujeito 16)

Em condição oposta aos aspectos de conteúdos, planos, métodos e recursos didáticos, em si mesmos considerados, na caracterização da prática nas escolas, aparece como fundamental, no âmbito do currículo, no sentido de terem sido/serem afetados por uma reforma, a organização e a dinâmica dos processos e das relações no interior das condições subjetivo-objetivas das escolas, e das suas relações com outros setores da sociedade.

Neste caso, na caracterização da identidade da prática escolar, importa, sobremaneira, o trabalho coletivo que se desenvolve nas escolas técnicas, cujos pilares seriam: os objetivos e a questão da qualificação e formação profissional, as concepções e práticas relativas às relações da escola com a indústria e o mercado de trabalho; e, ainda, as características dos sujeitos escolares que são conhecidas e respeitadas na instituição, que são consideradas como recursos facilitadores/ limitadores do trabalho escolar, que influenciam as relações formais (envolvendo questões de gestão) e informais entre eles, e que os tornam membros/não membros da escola.

A importância desses pilares é salientada, principalmente, quando os entrevistados negam a Reforma, criticando-a, e, em oposição, afirmam o que defendem. Entre as manifestações a respeito, sobre objetivos, encontram-se as seguintes:

Nós estávamos formando um cidadão, nós estávamos formando um técnico preparado para o quê? Preparado para assimilar $n$ informações quando ele fosse para o mercado de trabalho. Na realidade, a indústria ia fazer o papel dela naquele momento, ou bem ou mal, mas iria qualificar esse menino ou treinar esse rapaz para trabalhar naquela seção, naquela máquina e assim por diante. (Sujeito 01) 
No meu entendimento, o ensino integrado (nome atribuído ao Ensino Médio Técnico anterior à Reforma) concilia teoria e prática. Isso era o melhor que nós tínhamos para os nossos alunos. No Ensino Médio regular, que existe por aí, é muito teórico, desvinculado da sua prática. E o que nós fazemos aqui, já é dar uma introdução da formação técnica; quer dizer, o que é formar um técnico? É dentro desta linha, desta perspectiva de raciocínio, de saber interpretar, de saber pegar um manual e saber ler e se conduzir de uma maneira geral. Jamais uma escola técnica vai fazer o treinamento desse aluno. Nós não temos equipamento suficiente para isso, mas a gente pode dar a formação técnica para esse aluno. Mas o que seria essa formação profissional? Se você tem um equipamento, digamos, tem a parte mecânica, o funcionamento da peça mecânica. Você tem uma peça que funciona. Pode ser um liquidificador, uma lavadora, um carro, mas eles têm um motor... O conceito motor é que tem que ser visto, revisto e oferecido para o aluno. As especificidades, se é para carro, para isso ou aquilo, a empresa é que tem que fazer; porque isso é treinamento. $\mathrm{Na}$ escola, nós não temos condições de oferecer treinamento para cada equipamento que está no mercado. (Sujeito 08) (Grifos meus)

Minha crítica com relação à mudança, como foi feita, eu acho que é o mercado, daqui a uns 3,4 anos, é que vai sentir. Na formação do sistema tradicional, o aluno fazendo o colegial e fazendo o curso técnico junto... eu vejo que está se formando tanto a parte humana, quanto a técnica. Eu sempre vi dessa forma. (Sujeito 10)

A gente se preocupa, sim, neste sentido de formação geral do aluno. Um dos aspectos da reforma, em que nós ficamos meio atravessados, foi o demembramento desta parte do ensino integralizado em que os alunos pudessem ter uma cultura mais abrangente. (Sujeito 12)

Se o técnico vai atuar no mercado de trabalho, é uma outra nuança, porque não sei se tem lugar para todo mundo no mercado. (Sujeito 24)

Agora é só a formação básica, para você estar lá apertando parafuso mesmo. Vem de acordo a introdução dos módulos, da forma como foi feito, do ensino modular, vem exatamente suprir essa necessidade da restruturação que é fazer com que tenha profissionais assim, que, muitas vezes, por não terem acesso ao ensino de $2^{\circ}$ grau, da forma como deveriam, vão se sujeitar a salários baixos. É a mão-de-obra barata, não tão qualificada. E pode- 
ria ser muito mais(...) do que ela é hoje. São os apertadores de parafusos. O que nós estamos vendo é que a escola técnica, hoje, vai despejar no mercado uma mão-de-obra que não é tão crítica. (Sujeito 23)

A Reforma é porque eles acham que isso vai gerar mais emprego. Será que não é por aí? Tenho a impressão que sim. Acho que, em um ano e meio, a escola técnica pretende preparar mais trabalhadores para as indústrias. Tenho a impressão que é essa a visão que eles querem. $E$, também, porque a escola técnica é uma escola terminal. Fez o curso, supõe-se que ele já tenha o emprego amanhã; o que acho muito difícil. (Sujeito 16)

Com a grade que nós temos, o Ensino Médio nem é tão médio, mas também não é profissionalizante. Dessa forma, você fica num meio de caminho difícil, ainda, difícil de definir o que seremos, ao final desse processo. (Sujeito 08)

Ressaltam-se: a comparação entre o processo formativo que vinha sendo desenvolvido pelas escolas em pauta, na direção de uma formação mais global do aluno e que busca se aproximar de um processo de educação tecnológica, e uma formação mais restrita no contexto da Reforma, mais próxima de um processo de formação exclusivamente técnica, e, com isso, perda na identidade dessas escolas. Além disso fica evidente a existência de um trabalho formativo na escola, com o qual os sujeitos se comprometiam, para além de um treinamento ou da aquisição de competências específicas para se conseguir um emprego ou, mesmo, para apenas uma atuação competente no mercado de trabalho;

Sobre a relação escola e indústria, é interessante como ficam claras indagações da própria escola acerca das relações entre a Reforma e o denominado novo perfil demandado pelo setor produtivo, o que corrobora as discussões aqui já feitas acerca das contradições no interior dessas relações:

Eu fico perdida, agora, com relação à questão de se a Reforma estaria contrária ao que o próprio mercado está necessitando. Eu não sei a quem vai caber a formação desse técnico. (Sujeito 08)

Nós não temos capacidade para formar este pessoal com o perfil que as indústrias estão dizendo. Não vamos conseguir formar com essa finalidade... O Senai e o Senac também não conseguiriam. O curso que formava com esse perfil eles destruíram... (Sujeito 01) 
O profissional crítico, cidadão, é importante para o empresário. Claro que é mascarado... Mas sem custar dinheiro, sem custar o lucro. Mas para a empresa um cidadão criativo, consciente, é importante. Ele vai render muito... (Sujeito 15)

E sobre relações sociais na escola, a partir da Reforma, as dúvidas sobre a da identidade das escolas pesquisadas, que não consideram os alunos dos módulos como seus próprios alunos, fica bem exposta.

Mas eu vejo uma diferenciação muito grande entre o nosso aluno do curso médio e o nosso aluno do modular. Eles têm um comportamento diferenciado dos nossos próprios alunos. Até em termos disciplinares. (Sujeito 16)

Ao lado disso, o caráter impositivo das mudanças incomoda, sobremaneira, os sujeitos escolares, tal como a seguir:

Isso (trata-se da imposição da Reforma) me irrita profundamente, pelo desprezo e a desconsideração que todo este processo tem com a gente, com o povo e com os alunos. (Sujeito 01)

Finalmente, junto à importância dos sujeitos e das relações entre eles, os recursos financeiros e físico-materiais também aparecem como fundamentais na definição do trabalho escolar, em qualquer condição, de reforma ou não. Aliás, as condições físico-materiais das escola, nos planos do real e do possível, são mencionadas como definidoras do papel que estas desenvolvem e podem desenvolver, nos processos de qualificação e formação profissionais.

No entanto, os entrevistados reforçam a importância da competência dos sujeitos no trato com os recursos tecnológicos, e, mais uma vez, mencionam o trabalho coletivo na escola que integrava a formação geral com a formação profissional, conduzida por uma equipe de professores também integrados. Assim:

Penso que estamos no meio do caminho para sentir melhor o modular. Não sei se é treinamento, a perspectiva. E se for pela perspectiva de treinamento, acho que escolas não têm como viabilizar treinamento, porque os equipamentos são defasados. A gente não 
tem condições de manter, enquanto investimento em equipamento, a mesma situação de uma empresa, de uma indústria. É difícil. (Sujeito 08)

Por exemplo, dentro da área da mecânica, as máquinas que estão sendo usadas lá, não tem mais como... As empresas não usam mais isso. Usam é computador. E dinheiro para mudar? É esta verba que o governo recebeu que tinha de estar aí para trocar. (Sujeito 15)

Quando você fala em tecnologia é muito mais rápido aqui, por que? Porque eu tenho condições humanas. Materiais não, mas a humana eu tenho aqui dentro do Ensino Técnico. Eu posso me recorrer aos técnicos. Se eu tenho o curso de eletrônica, tenho vários colegas que dominam esta parte de informática. Então, é rápido. Ao passo que em uma outra escola não tem o material humano, sequer para começar o trabalho. (Sujeito 08)

Pelos depoimentos, mais uma vez expressa-se a consciência dos sujeitos escolares relativa aos limites do trabalho formativo das escolas de educação tecnológica nas condições da Reforma e, também da não Reforma.

As considerações anteriores ligam-se à definição de um conjunto de categorias referentes à prática pedagógica no ensino tecnológico, tal como ocorre nas escolas pesquisadas, e que aparece como síntese provisória das propriedades que caracterizariam essa prática histórico-concreta, expressando formas de sua existência: avaliação; clientela; currículo; evasão; aceso à escolarização; comunidade e escola; objetivos; profissionalização e escola; indústria, mercado de trabalho e escola; processos e relações sociais na escola; gestão e administração escolar; recursos escolares. Além dessas categorias, à luz dos objetivos da pesquisa, quando perguntados a respeito, os entrevistados se expressaram sobre as relações entre saber escolar e o desenvolvimento científico tecnológico, relacionando esse aspecto às mudanças societárias, as quais, a rigor, foram, no geral, bem lembradas pelos sujeitos ao se referirem à prática nas escolas.

O levantamento do número de manifestações referentes a cada uma das categorias encontradas evidencia a importância relativa dessas categorias como definidoras da prática escolar em geral, e em relação à Reforma, principalmente, em termos daquilo que seria mais ou menos vulnerável às intervenções externas na vida da escola. $\mathrm{O}$ quadro a seguir registra esses dados, corroborando a importância do currículo, 
e das relações sociais formais e informais na escola, além dos recursos na caracterização dessa prática.

Categorias da prática pedagógica no ensino tecnológico segundo manifestações dos entrevistados - 1998

\begin{tabular}{|l|c|c|}
\hline Categorias & No ensino tecnológico em geral & $\begin{array}{c}\text { Na condição } \\
\text { Reforma }\end{array}$ \\
\hline Acesso & 61 & 66 \\
\hline Avaliação & 24 & 34 \\
\hline Clientela & 51 & 73 \\
\hline Comunidade e escola & 39 & 21 \\
\hline Currículo (estrutura e organização) & 201 & 226 \\
\hline Evasão & 05 & 23 \\
\hline Gestão e administração & 136 & 103 \\
\hline Indústria, mercado de trabalho e escola & 98 & 25 \\
\hline Mudan as societárias e escola & 147 & 36 \\
\hline Objetivos & 70 & 27 \\
\hline Processos e relações sociais & 130 & 123 \\
\hline Profissionalização e escola & 131 & 66 \\
\hline Recursos & 191 & 88 \\
\hline $\begin{array}{l}\text { Saber escolar e desenvolvimento } \\
\text { científico tecnológico }\end{array}$ & 67 & 03 \\
\hline TOTAL & $\mathbf{1 3 5 1}$ & $\mathbf{9 1 3}$ \\
\hline
\end{tabular}

FONTE - Entrevistas realizadas com 24 sujeitos de escolas de educação tecnológica.

O conjunto de categorias delineado implica um conteúdo formativo de uma realidade escolar que luta por manter, sobretudo em um contexto adverso, nos limites implicados pela Reforma, o objetivo de um processo de educação tecnológica para todos, porquanto comprometido com a democratização da educação e o atendimento ás necessidades das camadas menos favorecidas da formação social brasileira.

\section{À Guisa de Conclusão}

As considerações anteriores apontam para algumas conclusões iniciais, nos limites deste trabalho, que evidenciam mais desacertos do que acertos na nova proposta curricular para o Ensino Médio, em termos da sua aproximação da denominada formação, educação tecnológica, pelo menos na perspectiva das instituições escolares de ensino tecnológico. 
Em primeiro lugar, cumpre salientar que, no âmbito dessas escolas, a atual Reforma de Ensino Médio implicaria uma reforma estrutural que transforma a identidade dessas escolas.

Pelo visto, no âmbito do chão de escola isso se daria não pelo fato de a Reforma, em suas diretrizes, expressar novas contradições de um novo estágio de acumulação capitalista. Mas, nesse âmbito, isso se daria pelo fato de essas diretrizes modificarem uma certa equação construída nas escolas, em que tempos, espaços e regras se integravam num dado projeto formativo de educação geral integrada com a formação profissional. Nas palavras de um dos sujeitos de uma das escolas, com as quais se trabalhou, as novas diretrizes estariam transformando a escola em um corredor: "...você anda quando quiser. Não criam (trata-se dos alunos) nenhum vínculo com a escola; isso, em termos de escola... não têm afinidade com ela. O que queriam é que fosse somente um lugar".

Esse lugar-corredor - espaço de uma proposta curricular que, no âmbito dos documentos legais, acaba por revigorar a dualidade estrutural do nível médio, de forma tão mais contundente quanto mais a encobre, e por favorecer a fragmentação no processo formativo escolar, pelo menos em termos das relações gerais entre a educação básica e a educação profissional e no interior desta, em particular - não se mostra tão favorável assim ao desenvolvimento de um conteúdo curricular que se aproxime de uma formação tecnológica, de uma educação tecnológica para todos, tal como aqui discutidas.

Dessa forma, sujeitos educativos, que defendem o desenvolvimento de um trabalho escolar na direção desta educação tecnológica, sem deixar que a integração entre formação geral e formação profissional fique bem à mercê do seu processamento residual e espontâneo pelo aprendiz trabalhador, questionam esse corredor. Ele não se coadunaria com os conteúdos formativos então desenvolvidos por espaços-escola historicamente comprometidos com a educação tecnológica para os trabalhadores, ainda que se reconheçam os limites desses espaços também nessa direção.

Levantam-se, então, algumas questões:

Em que medida a Reforma envolve não apenas uma proposta de mudanças no ensino de nível médio, mas de mudanças na escola de Ensino Médio, e, em particular, nas escolas de educação tecnológica? E na perspectiva destas, em que medida, a Reforma, ao invés de ampliar condições para a melhoria do ensino que se desenvolve nelas, não as estaria reduzindo? Quais as implicações disso para a materialização da proposta no chão da escola, a médio e longo prazos? Como reforçar a importância dos tempos e espaços escolares que não são apenas mediadores (corredores) entre o 
aluno e o mercado de trabalho? Como viabilizar a formação tecnológica na escola comprometida com a superação das relações de exclusão societárias? E a partir do novo corredor escolar, como superar a realidade da escola no mercado, na praça, pela possibilidade/realidade de uma praça na escola?

\section{Notas}

1. Ver, por exemplo; CEFET/MG, 1996.

2. Recorde-se, como já mencionado, que a educação profissional de nível médio (técnico) tem organização curricular própria e independente do Ensino Médio regular; o diploma de técnico de nível médio depende da conclusão do Ensino Médio regular; a educação profissional de nível básico é uma forma de educação não formal: há a possibilidade de a organização curricular da educação profissional de nível médio ser feita em módulos que podem ser cursados em diferentes instituições...

3. (...) indica parte da gravação que ficou inaudível.

Changes in the working world: Adjustments and errors in the curriculum proposal for high school (Resolution CNE 03/98 ) differences between technical formation and technological one

ABSTRACT: The text analyses the new curriculum proposal for High School, particularly referring to the professional education, focusing the differences between technical formation and technological, in the scopes of official speech and the proposal implantation. There's an approach to question the contradictions in the study of the relation between the proposal and the changes in the productive sector linked to the new demandings of the formation and professional qualification. Based on empirical research data, from the implantation of the reform in technical schools, the text discuss properties of the school practice in the technological teaching, showing the loss of identity from these schools, in the reform context, making it viable the formative process of techno logical education engaged with educational democratization.

\section{Referências Bibliográficas}

BRASIL. Decreto n. 2.208, de 17 abril de 1997. Regulamenta o parágrafo $2^{\circ}$ do art. 36 e os artigos 39 a 42 da Lei n. 9.394, de 20 de dezembro de 1996, que estabelece as diretrizes e bases da educação 
nacional. In: SINDOCEFET-PR/ANDES-SN. $A$ verdade sobre a reforma da educação profissional. Curitiba: Gráfica e Editora Popular, (s.d.).

MEC/Conselho Nacional de Educação. Câmara de Educação Básica. Parecer n.15, de $1^{\circ}$ de jun. de 1998.

MEC/Conselho Nacional de Educação. Câmara de Educação Básica. Resolução n.3, de 26 de jun. de 1998. Institui as Diretrizes Curriculares Nacionais para o Ensino Médio. 1998b.

CEFET-MG. Audiência pública. Deputado Federal Severiano Alves (PDT-BA); coletânea de textos apresentados. Belo Horizonte, CEFET/MG, 1996. 